\title{
Administration time difference of candesartin effect on albuminuria in type 2 diabetic patients
}

\author{
Hypertension Research (2009) 32, 527-528; doi:10.1038/hr.2009.49; published online 17 April 2009
}

To the editor:

An increase of albuminuria is predictive of overt diabetic nephropathy. Proteinuria has a circadian pattern, and diurnal changes in systemic and renal hemodynamics contribute to the circadian pattern of proteinuria. ${ }^{1,2}$ In normotensive insulin-dependent diabetic patients, the night time decrease of blood pressure is smaller if microlbuminuria is present, and high nocturnal blood pressure load is associated with an increase of albuminuria.,4 Nocturnal blood pressure rise is superior to predict worsening of albuminuria in elderly type 2 diabetic patients. ${ }^{5}$ It is supposed that nocturnal blood pressure control should be important in the prevention of diabetic nephropathy.

Renin-angiotensin system blockade is one of the effective strategies to reduce urinary protein excretion and to delay the progression to end-stage renal disease. ${ }^{6,7}$ Angiotensin II receptor blocker (ARB) is a basic antihypertensive treatment for type 2 diabetic patients with nephropathy. However, best time of ARB administration has not been studied well. We tried to answer when is best time of ARB, candesartin cilexetil, administration for the improvement of hypertension and urine albumin excretion in type 2 diabetic patients.

This was a randomized study conducted in Gunma University Hospital. Male and female patients with type 2 diabetes mellitus, $>18$ years of age were considered eligible for the study. Twenty-five outcoming type 2 diabetic patients (age; $55.9 \pm 3.1$ year old, 12 males, 13 females) with diabetic micro- or macro-albuminuria (urine albumin/creatinine index $>30 \mathrm{mg} \mathrm{g}^{-1}$ creatinine $(\mathrm{Cr})$ ) and elevated home blood pressure (systolic blood pressure $(\mathrm{SBP})>130 \mathrm{~mm} \mathrm{Hg}$ and/or diastolic blood pressure (DBP) $>80 \mathrm{~mm} \mathrm{Hg}$ ) were recruited in the study. Exclusion criteria included the following: age $<20$ year old, diabetic ketoacidosis, pregnancy, severe infection, serum potassium levels $>5.0$ mequiv $^{-1}$, serum Cr levels $>3.0 \mathrm{mg}$ per $100 \mathrm{ml}$, SBP $>180 \mathrm{~mm} \mathrm{Hg}$ and/or DBP > $120 \mathrm{mmHg}$. Previous treatment with other hypoglycemic agents or insulin injection continued with the same dose throughout the study. This study was approved by the Ethical Committee of Gunma University Hospital. Informed consent was obtained from all the patients. All patients were followed in our hospital until the end of this study.

The SBP and DBP were measured by automatic sphyngnomanometer (HEM7051T, OMRON corporation, Kyoto, Japan) at home after awaking in the morning, and the patients reported the results on the visit to the hospital. Urine specimen was also collected after measuring home blood pressure in the early morning on the same day visiting to the hospital.

All patients were randomly divided by using a closed envelope system into two groups; patients received candesartin cilexetil after breakfast (A group; $n=12$ ) and after dinner ( $P$ group; $n=13$ ). Initial dose of candesartin cilexetil was $4-8 \mathrm{mg} \mathrm{day}^{-1}$, and increased to the maximal dose of $12 \mathrm{mg} \mathrm{day}^{-1}$ according to the results of self-monitored home blood pressure levels after awaking in the early morning. Self-monitored home blood pressure and urine excretion of albumin at 12 weeks after the start of the treatment was compared with those at baseline.

Plasma glucose levels and urinary excretion of albumin were measured by using automatic analyzer with glucose oxidase method and turbidimetric immunoassay, respectively. Glycosylated $\mathrm{Hb} \mathrm{A}_{1 \mathrm{c}}$ levels were measured by the standardized high-performance liquid chromatography method (High Auto $\mathrm{A}_{1 \mathrm{c}}$ HA8150; ARKRAY Inc., Kyoto, Japan; normal range: $4.3-5.8 \%)$.
All data represent mean \pm s.e.m. The statistical analysis was performed by analysis of variance, followed by Student's $t$-test for the individual difference of the means. To compare the difference of chronological change of the data, paired $t$-test was used.

The average of final daily dose of candesartin cilexetil at 12 -week was $7.0 \pm 1.4 \mathrm{mg}$ in A group, $7.1 \pm 1.1 \mathrm{mg}$ in $\mathrm{P}$ group. Home systolic blood pressure decreased from $154.0 \pm 7.5$ to $139.8 \pm 5.4 \mathrm{~mm} \mathrm{Hg}$ in $\mathrm{A}$ group, and decreased from $153.4 \pm 7.4$ to $130.8 \pm 7.0 \mathrm{~mm} \mathrm{Hg}$ in $\mathrm{P}$ group. As shown in Figure 1, the percentage of the reduction of SBP $(\Delta \%$ SBP $)$ was significantly $(P<0.05)$ higher in $\mathrm{P}$ group $(82.7 \pm 2.2 \%)$ than $\mathrm{A}$ group $(91.5 \pm 3.4 \%)$, whereas there was no difference in the reduction of DBP $(\triangle \% \mathrm{DBP})$ between both groups $(P=0.198)$.

The urine albumin index (UAI) decreased from $564.9 .0 \pm 214.2 \mathrm{mgg}^{-1} \mathrm{Cr}$ to $541.8 \pm 239.2 \mathrm{mgg}^{-1} \mathrm{Cr}$ in $\mathrm{A}$ group, and decreased from $522.1 \pm 431.6 \mathrm{mgg}^{-1} \mathrm{Cr}$ to $352.3 \pm 300.7 \mathrm{mgg}^{-1} \mathrm{Cr}$ in $\mathrm{P}$ group. The improvement of UAI $(\Delta \% \mathrm{UAI})$, measured at the early morning, was significantly $(P<0.03)$ higher in $\mathrm{P}$ group $(51.5 \pm 9.1 \%)$ than A group $(97.6 \pm 15.2 \%)$ (Figure 1). There were no significant changes by candesartin cilexetil administration for 12 weeks in body weight, postprandial plasma glucose and $\mathrm{Hb} \mathrm{A}_{1 \mathrm{c}}$ levels in both groups.

We have first shown that candesartin administration time difference causes different influences on SBP measured at home after awaking in the morning and urine albumin excretion collected at home in the morning. The optimal dose of candesartan is $16 \mathrm{mg}$ daily for renoprotection, as reflected by short-term reduction of albuminuria in 24-h urine samples, in hypertensive type 2 diabetic patients with nephropathy. ${ }^{8}$ However, low-dose candesartan can also prevent early kidney damage 


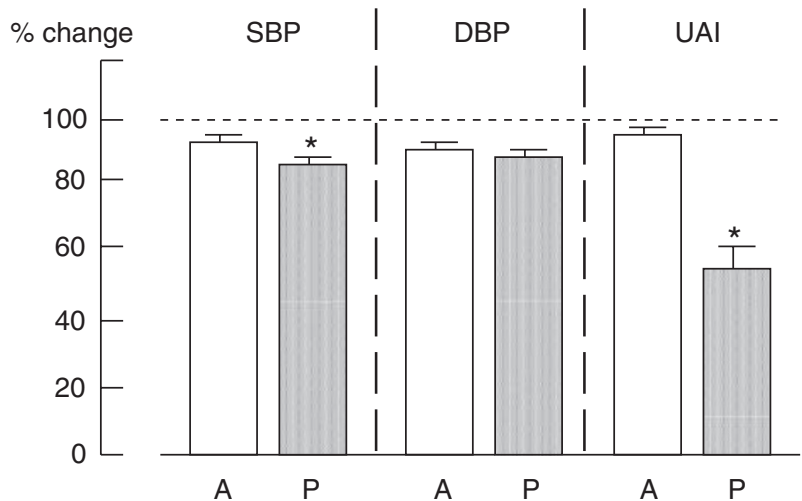

Figure 1 Changes of self-monitored home systolic blood pressure (SBP), diastolic blood pressure (DBP) and urine albumin index (UAI) after awaking in the early morning after 12-week candesartin cilexetil administration after the breakfast $(A)$ and dinner $(P)$. The percentage of change in each parameter was calculated by dividing 12 -week value by its baseline value. ${ }^{*} P<0.05$ vs. A group.

in type 2 diabetic patients with mildly higher blood pressure independently of its hypotensive action. ${ }^{9}$ Candesartan cilexetil has been also reported to show a dose-related reduction in proteinuria after 12 weeks of treatment, and candesartin cilexetil has been thought to be useful in reducing proteinuria in diabetic patients. ${ }^{10}$ In an earlier study, 5.8\% reduction of albuminuria was found, in contrast to $32.2 \%$ increase in the placebo group, and a $0.8 \%$ increase in the $2 \mathrm{mg}$ group. In this study, the average of final daily dose of candesartin cilexetil at 12-week was about $7 \mathrm{mg}$ in both group. Urine samples were collected in the early morning, and $48.5 \%$ reduction of UAI was found in $\mathrm{P}$ group, in contrast to $2.4 \%$ reduction in A group. It was indicated that candesartin cilexetil had better be administered in the evening, resulting in the effective reduction of urine albumin excretion with significantly potent hypotensive effect in the early morning. However, the degree of $\%$ SBP appears to be dissociated from the degree of the reduction of UAI. The observed improvement of urine albumin excretion may be attributable to both antihypertensive effects and direct effects on the renal hemo- dynamics of candesartin cilexetil. There may be a difference in the effects of candesartan cilexetil on the systemic circulation and renal hemodynamics. However, further studies including ambulatory blood pressure monitoring for more than $24 \mathrm{~h}$ should be necessary to finally explain the dissociation, as this study examined only changes of home blood pressure in the early morning. It is supposed that diabetic patients with nephropathy had better take ARB in the evening to reduce morning hypertension and albuminuria after awaking in the morning, although further studies should be necessary to determine if the improvement of the UAI in the spot urine collection after awaking can contribute to the delay of the development to end-stage renal disease.

Hiroyuki Shimizu, Yutaka Uehara, Aya Ohsaki, Shuichi Okada and Masatomo Mori

Department of Medicine and Molecular Science, Gunma University Graduate School of Medicine, Maebashi, Japan E-mail: hshimizu@showa.gunma-u.ac.jp
1 Koopman MG, Krediet RT, Koomen GCM, Strackee J, Arisz L. Circadian rhythm of proteinuria: consequences of the use of urinary protein:creatinine ratios. Nephol Dial Transplant 1989; 4: 9-14.

2 Koopman MG, Krediet RT, Zuyderhoudt FJM, Moor EAM, Arisz L. A circadian rhythm of proteinuria in patients with the nephritic syndrome. Clin Sci 1985; 69: 395-401.

3 Voros P, Lengyel Z, Nagy V, Nemeth C, Rosivall L, Kammerer $L$. Diurnal blood pressure variation and albuminuria in normotensive patients with insulindependent diabetes mellitus. Nephrol Dial Transplant 1998; 13: 2257-2260.

4 Palmas W, Pickering T, Teresi J, Schwartz JE, Eguchi K, Field L, Weinstock RS, Shea S. Nocturnal blood pressure elevation predicts progression of albuminuria in ealderly people with type 2 diabetes. J Clin Hypertens 2008; 10: 12-20.

5 Lengyel Z, Rosivall L, Nemeth C, Toth LK, Nagy V, Mihaly M, Kammerer L, Voros P. Diurnal blood pressure pattern may predict the increase of urinary albumin excretion in normotensive normoalbuminuric type 1 diabetes mellitus patients. Diabetes Res Clin Pract 2003; 62: 159-167.

6 Brenner BM, Cooper ME, de Zeeuw D, Keane WF, Mitch WE, Parving $\mathrm{H}-\mathrm{H}$, Remuzzi G, Snapinn SM, Zhang Z, Shahinfar S, RENAAL study investigators. Effects of losartin on renal and cardiovascular outcomes in patients with type 2 diabetes and nephropathy. N Engl J Med 2001; 345: 861-869.

7 Parving $\mathrm{H}-\mathrm{H}$, Lehnert $\mathrm{H}$, Brochner-Mortensen J, Gomis R, Andersen S, Arner P, the irbesartan in patients with type 2 diabetes and microalbuminuria study group. The effect of irbesartan on the development of diabetic nephropathy in patients with type 2 diabetes. N Engl J Med 2001; 345: $870-878$.

8 Rossing K, Christensen PK, Hansen BV, Carstensen B, Parving $\mathrm{HH}$. Optimal dose of candesartin for renoprotection in type 2 diabetic patients with nephropathy: a double-blind randomized cross-over study. Diabetes Care 2003; 26: 150-155.

9 Murayama S, Hirano T, Sakaue T, Okada K, Ikejiri R, Adachi M. Low-dose candesartin cilexetil prevents early kidney damage in type 2 diabetic patients with mildly elevated blood pressure. Hypertens Res 2003; 26: 453-458.

10 Haneda M, Kikkawa R, Sakai H, Kawamori R, Candesartin in Diabetic nephropathy Study Group. Antiproteinuric effect of candesartin cilexetil in Japanese subjects with type 2 diabetes and nephropathy. Diabetes Res Clin Pract 2004; 66: 87-95. 